\title{
Fixed point of multivalued integral type of contraction mappings
}

\author{
Mila Stojaković ${ }^{*}$, Ljiljana Gajić2 ${ }^{2}$ Tatjana Došenovićc and Biljana Carić
}

\footnotetext{
"Correspondence: stojakovic@sbb.rs

${ }^{1}$ Faculty of Technical Science,

University of Novi Sad, Novi Sad,

Serbia

Full list of author information is

available at the end of the article
}

\begin{abstract}
In this paper the fixed point of multivalued mapping is considered. A generalization of the well-known Nadler contraction principle, the Khan contraction theorem and the fixed point theorem in complete metric space with a convex structure is proved. The main result of the paper is formulated by three theorems where the mappings, defined over the complete metric space, are assumed to satisfy some integral type of contraction.
\end{abstract}

MSC: Primary $54 \mathrm{H} 25$; secondary $47 \mathrm{H} 10$

Keywords: fixed point; Cauchy sequence; complete metric space; convex structure; altering distance function

\section{Introduction}

Fixed point theory in the framework of metric spaces is one of the most powerful and useful tools in nonlinear functional analysis. The intrinsic subject of this theory is concerned with the conditions for the existence, uniqueness and exact methods of evaluation of fixed point of a mapping. The application of fixed point theorems is remarkable in a wide scale of mathematical, engineering, economic, physical, computer science and other fields of science. The Banach contraction principle [1] is a simplest and limelight result in this direction. In many papers, following the Banach contraction principle, the existence of weaker contractive conditions combined with stronger additional assumptions on the mapping or on the space is investigated. Moreover, since all these results are based on an iteration process, they can be implemented in almost all branches of quantitative sciences.

Nadler [2] initiated the study of fixed point for multivalued contraction mappings. On the other hand, Branciari [3] generalized the Banach contraction principle for a singlevalued mapping by using an integral type of contraction. Both of these results were extended and applied by many authors, and we quote some of them [4-12]. Also, we refer to the paper of Khan et al. [13] which improved the metric fixed point theory by introducing a control function called an altering distance function.

In this paper we present the generalizations of the Banach contraction principle on multivalued mappings which satisfy integral type of contraction condition. These theorems are inspired by Nadler's and Khan's results. Also, the theorem for nonexpansive integral type multivalued mapping in a complete metric space with convex structure (introduced by Takahashi in [14]) is proved.

(C) 2015 Stojaković et al. This article is distributed under the terms of the Creative Commons Attribution 4.0 International License (http://creativecommons.org/licenses/by/4.0/), which permits unrestricted use, distribution, and reproduction in any medium, provided you give appropriate credit to the original author(s) and the source, provide a link to the Creative Commons license, and indicate if changes were made. 


\section{Preliminaries}

Throughout the paper, the standard notations and terminology of fixed point theory are used. For the convenience of the reader, we recall some definitions and statements which will be used in what follows.

Let $(X, d)$ be a metric space. We denote by $B(X)$ the set of all nonempty bounded subsets of $X$, by $\mathrm{CB}(X)$ the set of all nonempty closed and bounded subsets of $X$, by $\mathrm{CC}(X)$ the set of all nonempty compact subsets of $X$. The Hausdorff distance $H: \mathrm{CB}(X) \times \mathrm{CB}(X) \rightarrow[0, \infty)$ is defined by

$$
H(A, B)=\max \left\{\sup _{x \in B} d(x, A), \sup _{y \in A} d(y, B)\right\},
$$

where $d(x, A)=\inf _{y \in A} d(x, y)$. The function $\delta: B(X) \times B(X) \rightarrow[0, \infty)$ is defined by

$$
\delta(A, B)=\sup \{d(a, b): a \in A, b \in B\} .
$$

If $A=\{a\}$ is a singleton, we write $\delta(A, B)=\delta(a, B)$, and if $B=\{b\}$, then $\delta(A, B)=\delta(a, b)=$ $d(a, b)$. It is easy to show that for all $A, B, C \in B(X)$ the following is satisfied:

$$
\begin{aligned}
& \delta(A, B)=\delta(B, A) \geq 0, \quad \delta(A, B) \leq \delta(A, C)+\delta(C, B), \\
& \delta(A, A)=\operatorname{diam} A, \quad \delta(A, B)=0 \quad \Leftrightarrow \quad A=B=\{a\} .
\end{aligned}
$$

Definition 2.1 Let $(X, d)$ be a metric space, $\mathcal{P}(X)$ be the partitive set of $X$, and $T: X \rightarrow$ $\mathcal{P}(X) \backslash \emptyset$. The mapping $T$ is proximal if and only if for every $x \in X$ there exists $x^{\prime} \in T x$ such that $d(x, T x)=d\left(x, x^{\prime}\right)$.

Definition 2.2 Let $(X, d)$ be a metric space, $\mathcal{P}(X)$ be the partitive set of $X$, and $T: X \rightarrow$ $\mathcal{P}(X) \backslash \emptyset$. The mapping $T$ is weakly demicompact if and only if for every sequence $\left\{x_{n}\right\}_{n \in \mathbb{N}}$ from $X$ such that $x_{n+1} \in T x_{n}, n \in \mathbb{N}$ and $\lim _{n \rightarrow \infty} d\left(x_{n+1}, x_{n}\right)=0$, there exists a convergent subsequence $\left\{x_{n_{k}}\right\}_{k \in \mathbb{N}}$.

Definition 2.3 Ultrametric space $(X, d)$ is a special kind of metric space in which the triangle inequality is replaced by the stronger one

$$
d(x, y) \leq \max \{d(x, z), d(z, y)\}
$$

Khan et al. [13] improved the fixed point theory in metric spaces by introducing a control function called an altering distance function.

Definition 2.4 A function $\psi:[0, \infty) \rightarrow[0, \infty)$ is an altering distance function if

(i) $\psi$ is increasing and continuous,

(ii) $\psi(t)=0$ if and only if $t=0$.

Let $\boldsymbol{\Psi}=\{\psi:[0, \infty) \rightarrow[0, \infty), \psi$ is an altering distance function $\}$ be the class of functions which satisfy conditions (i) and (ii).

Definition 2.5 A metric space $(X, d)$ has a convex structure in the sense of Takahashi if there exists a mapping $W: X \times X \times[0,1] \rightarrow X$ such that for every $x, y, u \in X$ and every 
$s \in[0,1]$,

$$
\begin{aligned}
& d(u, W(x, y, s)) \leq s d(u, x)+(1-s) d(u, y), \\
& W(x, y, 1)=x \quad \text { and } \quad W(x, y, 0)=y .
\end{aligned}
$$

We denote a metric space $(X, d)$ with a convex structure $W$ by $(X, d, W)$.

Definition 2.6 By $\boldsymbol{\Phi}$ we denote the class of functions $\varphi:[0, \infty) \rightarrow[0, \infty)$ which satisfy the following conditions:

(i) $\varphi$ is Lebesgue integrable, summable on each compact subset of $[0,+\infty)$,

(ii) $\int_{0}^{\varepsilon} \varphi(t) d t>0$ for each $\varepsilon>0$.

Lemma $2.7[15]$ Let $\left\{r_{n}\right\}_{n \in \mathbb{N}}$ be a nonnegative sequence and $\varphi \in \boldsymbol{\Phi}$. Then

$$
\lim _{n \rightarrow \infty} \int_{0}^{r_{n}} \varphi(t) d t=0
$$

if and only if $\lim _{n \rightarrow \infty} r_{n}=0$.

\section{Contraction of Nadler type}

Before we formulate the theorem which is a generalization of Nadler $q$-contraction using integral type of contraction, we present a few lemmas which will be used in that theorem.

Lemma 3.1 Let $(X, d)$ be a metric space and $T: X \rightarrow B(X)$, and let there exist $q \in(0,1)$ such that for every $x, y \in X$ and every $\delta>0$,

$$
\int_{0}^{H(T x, T y)+\delta} \varphi(t) d t \leq q \int_{0}^{d(x, y)+\delta / q} \varphi(t) d t
$$

where $\varphi \in \mathbf{\Phi}$. Then there exists a sequence $\left\{x_{n}\right\}_{n \in \mathbb{N}}, x_{n+1} \in T x_{n}$ such that $\lim _{n \rightarrow \infty} d\left(x_{n}\right.$, $\left.x_{n+1}\right)=0$.

Proof For any $x_{0} \in X, x_{1} \in T x_{0}$, there exists $x_{2} \in T x_{1}$ such that

$$
d\left(x_{1}, x_{2}\right) \leq H\left(T x_{0}, T x_{1}\right)+q^{2} .
$$

From (2) we have

$$
\int_{0}^{d\left(x_{1}, x_{2}\right)} \varphi(t) d t \leq \int_{0}^{H\left(T x_{0}, T x_{1}\right)+q^{2}} \varphi(t) d t \leq q \int_{0}^{d\left(x_{0}, x_{1}\right)+q} \varphi(t) d t .
$$

Further, there exists $x_{3} \in T x_{2}$ such that $d\left(x_{2}, x_{3}\right) \leq H\left(T x_{1}, T x_{2}\right)+q^{4}$ and, consequently,

$$
\int_{0}^{d\left(x_{2}, x_{3}\right)} \varphi(t) d t \leq \int_{0}^{H\left(T x_{1}, T x_{2}\right)+q^{4}} \varphi(t) d t \leq q \int_{0}^{d\left(x_{1}, x_{2}\right)+q^{3}} \varphi(t) d t .
$$

By (3)

$$
d\left(x_{1}, x_{2}\right)+q^{3} \leq H\left(T x_{0}, T x_{1}\right)+q^{2}+q^{3},
$$


and by (4)

$$
\int_{0}^{d\left(x_{2}, x_{3}\right)} \varphi(t) d t \leq q \int_{0}^{H\left(T x_{0}, T x_{1}\right)+q^{2}+q^{3}} \varphi(t) d t \leq q^{2} \int_{0}^{d\left(x_{0}, x_{1}\right)+q+q^{2}} \varphi(t) d t
$$

Continuing the process, we form the sequence $\left\{x_{n}\right\}_{n \in \mathbb{N}_{0}}, x_{n+1} \in T x_{n}$ such that

$$
\begin{aligned}
\int_{0}^{d\left(x_{n}, x_{n+1}\right)} \varphi(t) d t & \leq q^{n} \int_{0}^{d\left(x_{0}, x_{1}\right)+q+q^{2}+\cdots+q^{n}} \varphi(t) d t \leq \cdots \\
& \leq q^{n} \int_{0}^{d\left(x_{0}, x_{1}\right)+q /(1-q)} \varphi(t) d t, \quad n \in \mathbb{N} .
\end{aligned}
$$

Letting $n \rightarrow \infty$ we conclude that

$$
\lim _{n \rightarrow \infty} \int_{0}^{d\left(x_{n}, x_{n+1}\right)} \varphi(t) d t=0
$$

and using Lemma 2.7, $\lim _{n \rightarrow \infty} d\left(x_{n}, x_{n+1}\right)=0$.

Remark 3.2 Notice that for $\varphi(t) \equiv 1$ we get a Nadler $q$-contraction. Also, if we suppose that $T: X \rightarrow B(X)$ is a proximal mapping, the condition in Lemma 3.1 expressed by the inequality (2) can be reduced to

$$
\int_{0}^{H(T x, T y)} \varphi(t) d t \leq q \int_{0}^{d(x, y)} \varphi(t) d t
$$

In the next three lemmas, imposing some additional assumptions on mapping $T$ (Lemma 3.3), space $X$ (Lemma 3.4) or function $\varphi$ (Lemma 3.5), we can prove that the sequence $\left\{x_{n}\right\}_{n \in \mathbb{N}}$ from the last lemma has a Cauchy subsequence or is a Cauchy sequence itself. The proofs are elementary, so they are omitted.

Lemma 3.3 Let all conditions of Lemma 3.1 be satisfied and the mapping $T$ be weakly demicompact. Then the sequence $\left\{x_{n}\right\}_{n \in \mathbb{N}}$ has a Cauchy subsequence $\left\{x_{n_{k}}\right\}_{k \in \mathbb{N}}$.

Lemma 3.4 Let $(X, d)$ be an ultrametric space and all conditions of Lemma 3.1 be satisfied. Then the sequence $\left\{x_{n}\right\}_{n \in \mathbb{N}}$ is a Cauchy sequence.

Lemma 3.5 Let all conditions of Lemma 3.1 be satisfied and the function $\varphi \in \boldsymbol{\Phi}$ be such that $\int_{0}^{a+b} \varphi(t) d t \leq \int_{0}^{a} \varphi(t) d t+\int_{0}^{b} \varphi(t) d t$ for all $a, b \in[0, \infty)$. Then the sequence $\left\{x_{n}\right\}_{n \in \mathbb{N}}$ is a Cauchy sequence.

Finally, in order to prove the fixed point result for the integral type of contraction mapping satisfying (2), we use the last three lemmas.

Theorem 3.6 Let $(X, d)$ be a complete metric space. If the conditions of Lemma 3.3, Lemma 3.4 or Lemma 3.5 are satisfied, then the mapping $T$ has a fixed point.

Proof Let us consider the first case when all the conditions of Lemma 3.3 are satisfied. Then the sequence $\left\{x_{n}\right\}_{n \in \mathbb{N}}$ has a Cauchy subsequence $\left\{x_{n_{k}}\right\}_{k \in \mathbb{N}}$ and $\lim _{k \rightarrow \infty} x_{n_{k}}=x^{*}$. It 
remains to prove that $x^{*} \in T x^{*}$. Suppose the contrary, i.e., $d\left(x^{*}, T x^{*}\right)=\eta>0$. Using

$$
\begin{aligned}
& d\left(x^{*}, T x^{*}\right) \leq d\left(x^{*}, x_{n_{k}+1}\right)+d\left(x_{n_{k}+1}, T x^{*}\right) \leq d\left(x^{*}, x_{n_{k}}\right)+d\left(x_{n_{k}+1}, x_{n_{k}}\right)+d\left(x_{n_{k}+1}, T x^{*}\right), \\
& d\left(x_{n_{k}+1}, T x^{*}\right) \leq H\left(T x_{n_{k}}, T x^{*}\right) \leq H\left(T x_{n_{k}}, T x^{*}\right)+\delta, \quad \delta>0
\end{aligned}
$$

and (2), putting $\delta=q \eta$, we have

$$
\int_{0}^{d\left(x_{n_{k}+1}, T x^{*}\right)} \varphi(t) d t \leq \int_{0}^{H\left(T x_{n_{k}}, T x^{*}\right)+q \eta} \varphi(t) d t \leq q \int_{0}^{d\left(x_{n_{k}}, x^{*}\right)+\eta} \varphi(t) d t, \quad n \in \mathbb{N} .
$$

Letting $k \rightarrow \infty$ in (5) we have

$$
\int_{0}^{\eta} \varphi(t) d t \leq q \int_{0}^{\eta} \varphi(t) d t
$$

which contradicts the assumption that $d\left(x^{*}, T x^{*}\right)=\eta>0$. Hence $d\left(x^{*}, T x^{*}\right)=0$. Since $T x^{*}$ is a closed set, $x^{*} \in T x^{*}$.

The proof for other two cases is similar, so it is omitted.

\section{Contraction via altering distance function}

The next theorem is a generalization of the well-known and most cited result presented in [13]. The mapping we consider is multivalued and the contraction inequality is of integral type.

Theorem 4.1 Let $(X, d)$ be a metric space, $T: X \rightarrow B(X)$ and $\psi \in \Psi$. Let $k$ be a decreasing function, $k:[0, \infty) \rightarrow[0,1)$ such that for every $x, y \in X, x \neq y$,

$$
\psi\left(\int_{0}^{\delta(T x, T y)} \varphi(t) d t\right) \leq k(d(x, y)) \psi\left(\int_{0}^{d(x, y)} \varphi(t) d t\right)
$$

where $\varphi \in \mathbf{\Phi}$. Then $T$ has a unique fixed point $x^{*} \in X,\left\{x^{*}\right\}=T x^{*}$.

Proof Let $x_{0} \in X$. If $\left\{x_{0}\right\}=T x_{0}$, then $x_{0}=x^{*}$. If $\left\{x_{0}\right\} \neq T x_{0}$, then there exists $x_{1} \in T x_{0}$, $x_{0} \neq x_{1}$. Condition (6) implies that

$$
\psi\left(\int_{0}^{\delta\left(T x_{0}, T x_{1}\right)} \varphi(t) d t\right) \leq k\left(d\left(x_{0}, x_{1}\right)\right) \psi\left(\int_{0}^{d\left(x_{0}, x_{1}\right)} \varphi(t) d t\right)<\psi\left(\int_{0}^{d\left(x_{0}, x_{1}\right)} \varphi(t) d t\right) .
$$

By the same arguments if $\left\{x_{1}\right\}=T x_{1}$, then $x_{1}=x^{*}$, otherwise there exists $x_{2} \in T x_{1}, x_{2} \neq x_{1}$. Since $d\left(x_{1}, x_{2}\right) \leq \delta\left(T x_{0}, T x_{1}\right)$, from increasingness of $\psi$ and (7) we obtain that

$$
d\left(x_{1}, x_{2}\right)<d\left(x_{0}, x_{1}\right)
$$

Repeating this procedure, we construct the sequence $\left\{x_{n}\right\}_{n \in \mathbb{N}}$ such that $x_{n+1} \in T x_{n}$ and

$$
0<d\left(x_{n}, x_{n+1}\right)<d\left(x_{n-1}, x_{n}\right)<\cdots<d\left(x_{0}, x_{1}\right) .
$$


Since the sequence $\left\{d\left(x_{n}, x_{n+1}\right)\right\}_{n \in \mathbb{N}}$ is decreasing and bounded from below, it is convergent and

$$
\lim _{n \rightarrow \infty} d\left(x_{n}, x_{n+1}\right)=p
$$

where $p \leq d\left(x_{n}, x_{n+1}\right)$ for all $n \in \mathbb{N}$. If we assume that $p>0$, then relation (6) and decreasingness of the function $k$ yields

$$
\begin{aligned}
& \psi\left(\int_{0}^{d\left(x_{n}, x_{n+1}\right)} \varphi(t) d t\right) \\
& \quad \leq \psi\left(\int_{0}^{\delta\left(T x_{n-1}, T x_{n}\right)} \varphi(t) d t\right) \\
& \quad \leq k\left(d\left(x_{n-1}, x_{n}\right)\right) \psi\left(\int_{0}^{d\left(x_{n-1}, x_{n}\right)} \varphi(t) d t\right) \\
& \quad \leq k(p) \psi\left(\int_{0}^{d\left(x_{n-1}, x_{n}\right)} \varphi(t) d t\right) .
\end{aligned}
$$

Letting $n \rightarrow \infty$ in (8) gives

$$
\psi\left(\int_{0}^{p} \varphi(t) d t\right) \leq k(p) \psi\left(\int_{0}^{p} \varphi(t) d t\right)<\psi\left(\int_{0}^{p} \varphi(t) d t\right)
$$

which is a contradiction. So $p=0$.

It remains to prove that the sequence $\left\{x_{n}\right\}_{n \in \mathbb{N}}$ is a Cauchy sequence. Suppose the contrary. Then there exist $\varepsilon>0$ and infinitely many pairs $\left(x_{i}, x_{j}\right), d\left(x_{i}, x_{j}\right) \geq \varepsilon$. The subsequence of pairs $\left\{\left(x_{i_{m}}, x_{\left.j_{m}\right)}\right\}_{m \in \mathbb{N}}\right.$, where $i_{m}<j_{m}$ for all $m \in \mathbb{N}$, is chosen to satisfy the following property:

$$
d\left(x_{i_{m}}, x_{j_{m}}\right) \geq \varepsilon, \quad d\left(x_{i_{m}}, x_{s}\right)<\varepsilon, \quad \text { for all } s \in\left\{i_{m}+2, \ldots, j_{m}-1\right\} .
$$

Then

$$
\varepsilon \leq d\left(x_{i_{m}}, x_{j_{m}}\right) \leq d\left(x_{i_{m}}, x_{i_{m}-1}\right)+d\left(x_{i_{m}-1}, x_{j_{m}}\right)<\varepsilon+d\left(x_{i_{m}}, x_{i_{m}-1}\right),
$$

and letting $m \rightarrow \infty$ we obtain

$$
\varepsilon \leq \lim _{m \rightarrow \infty} d\left(x_{i_{m}}, x_{j_{m}}\right) \leq \varepsilon
$$

i.e.,

$$
\lim _{m \rightarrow \infty} d\left(x_{i_{m}}, x_{j_{m}}\right)=\varepsilon
$$

Using

$$
d\left(x_{i_{m}}, x_{j_{m}}\right) \leq d\left(x_{i_{m}}, x_{i_{m}-1}\right)+d\left(x_{i_{m}-1}, x_{j_{m}-1}\right)+d\left(x_{j_{m}-1}, x_{j_{m}}\right),
$$


we deduce that

$$
\varepsilon=\lim _{m \rightarrow \infty} d\left(x_{i_{m}}, x_{j_{m}}\right)=0+\lim _{m \rightarrow \infty} d\left(x_{i_{m}-1}, x_{j_{m}-1}\right)+0
$$

that is, $\lim _{m \rightarrow \infty} d\left(x_{i_{m}-1}, x_{j_{m}-1}\right)=\varepsilon$. Consequently, there exists $m_{0} \in \mathbb{N}$ such that for all $m>$ $m_{0}, d\left(x_{i_{m}-1}, x_{j_{m}-1}\right) \geq \frac{\varepsilon}{2}$. Hence $k\left(d\left(x_{i_{m}-1}, x_{j^{-1}}\right)\right) \leq k\left(\frac{\varepsilon}{2}\right)$ for all $m>m_{0}$. Recalling that $x_{i_{m}} \in$ $T x_{i_{m}-1}$ and $x_{j_{m}} \in T x_{j_{m}-1}$, we have

$$
\begin{aligned}
& \psi\left(\int_{0}^{d\left(x_{i_{m}}, x_{j m}\right)} \varphi(t) d t\right) \\
& \quad \leq \psi\left(\int_{0}^{\delta\left(T x_{i_{m}-1}, T x_{j_{m}-1}\right)} \varphi(t) d t\right) \\
& \quad \leq k\left(d\left(x_{i_{m}-1}, x_{j_{m}-1}\right)\right) \psi\left(\int_{0}^{d\left(x_{i_{m-1},}, x_{j_{m}-1}\right)} \varphi(t) d t\right) \\
& \quad \leq k\left(\frac{\varepsilon}{2}\right) \psi\left(\int_{0}^{d\left(x_{i_{m-1}}, x_{j_{m-1}}\right)} \varphi(t) d t\right)
\end{aligned}
$$

for all $m>m_{0}$, and when $m \rightarrow \infty$ we get

$$
\psi\left(\int_{0}^{\varepsilon} \varphi(t) d t\right) \leq k\left(\frac{\varepsilon}{2}\right) \psi\left(\int_{0}^{\varepsilon} \varphi(t) d t\right)<\psi\left(\int_{0}^{\varepsilon} \varphi(t) d t\right) .
$$

Obviously, the last inequality cannot be true. So, the sequence $\left\{x_{n}\right\}_{n \in \mathbb{N}}$ is a Cauchy sequence, and since the space is complete, there exists $x^{*} \in X$ such that $\lim _{n \rightarrow \infty} x_{n}=x^{*}$.

Next we prove that $\delta\left(x^{*}, T x^{*}\right)=0$. Let $\rho_{n}=d\left(x_{n}, x^{*}\right)$. Since for all $n \in \mathbb{N}, x_{n+1} \in T x_{n}$, we conclude that

$$
\begin{aligned}
\psi\left(\int_{0}^{\delta\left(x_{n+1}, T x^{*}\right)} \varphi(t) d t\right) & \leq \psi\left(\int_{0}^{\delta\left(T x_{n}, T x^{*}\right)} \varphi(t) d t\right) \\
& \leq k\left(\rho_{n}\right) \psi\left(\int_{0}^{\rho_{n}} \varphi(t) d t\right)<\psi\left(\int_{0}^{\rho_{n}} \varphi(t) d t\right) .
\end{aligned}
$$

Knowing that $\rho_{n}$ converges to 0 when $n \rightarrow \infty$, by (13), $\lim _{n \rightarrow \infty} \delta\left(x_{n+1}, T x^{*}\right)=0$. The relation

$$
\delta\left(x^{*}, T x^{*}\right) \leq d\left(x^{*}, x_{n+1}\right)+\delta\left(x_{n+1}, T x^{*}\right)=\rho_{n}+\delta\left(x_{n+1}, T x^{*}\right)
$$

together with previous conclusion gives $\left\{x^{*}\right\}=T x^{*}$.

Uniqueness of the fixed point $x^{*}$ follows from condition (6).

\section{Nonexpansive mapping in a space with a convex structure}

Definition 5.1 A metric space with a convex structure $(X, d, W)$ defined by (1) satisfies condition $(*)$ if for every $x, y, z, \in X$ and every $s \in[0,1]$,

$(*) \quad \int_{0}^{d(W(x, z, s), W(y, z, s))} \varphi(t) d t \leq s \int_{0}^{d(x, y)} \varphi(t) d t$,

where $\varphi \in \boldsymbol{\Phi}$. 
Theorem 5.2 Let a complete metric space with a convex structure $(X, d, W)$ satisfy condition $(*)$, and let $T: X \rightarrow \mathrm{CB}(X)$ be such that for every $x, y \in X$,

$$
\int_{0}^{\delta(T x, T y)} \varphi(t) d t \leq \int_{0}^{d(x, y)} \varphi(t) d t
$$

$\varphi \in \boldsymbol{\Phi}$. If a convex structure $W$ is continuous with respect to the first variable and if $\overline{T(X)}$ is compact, then there exists $z^{*} \in X$ such that $\left\{z^{*}\right\}=T z^{*}$.

Proof Fix any $x_{0} \in X$. Let $\left\{k_{n}\right\}_{n \in \mathbb{N}}$ be a sequence from $(0,1)$ such that $\lim _{n \rightarrow \infty} k_{n}=1$, and let

$$
T_{n} x=\bigcup_{z \in T x} W\left(z, x_{0}, k_{n}\right)=W\left(T x, x_{0}, k_{n}\right) \subseteq X
$$

We split the proof into four steps.

Step 1. First we show that the set $T_{n} x$ is a compact subset of $X$ for every $x \in X$. The set $T_{n} x$ is a union of $W\left(z, x_{0}, k_{n}\right) \subset X, z \in T x$, which implies that $T_{n} x \subseteq X$. To prove the compactness of $T_{n} x$, let $\left\{\alpha_{i}\right\}_{i \in \mathbb{N}} \subset T_{n} x$. The definition of the set $T_{n} x$ provides the existence of the sequence $\left\{\beta_{i}\right\}_{i \in \mathbb{N}} \subset T x$, where $\alpha_{i}=W\left(\beta_{i}, x_{0}, k_{n}\right)$. Since $\overline{T(X)}$ is compact, the set $T x \subset$ $\overline{T(X)}$ is compact too, which implies the existence of a convergent subsequence $\left\{\beta_{i_{m}}\right\}_{m \in \mathbb{N}} \subset$ $\left\{\beta_{i}\right\}_{i \in \mathbb{N}} \subset T x, \lim _{m \rightarrow \infty} \beta_{i_{m}}=\beta \in T x$. Recalling (15) and the continuity of $W$ with respect to the first variable, the related subsequence $\left\{\alpha_{i_{m}}\right\}_{m \in \mathbb{N}} \subset\left\{\alpha_{i}\right\}_{i \in \mathbb{N}} \subset T_{n} x$ is also convergent and

$$
\lim _{m \rightarrow \infty} \alpha_{i_{m}}=\lim _{m \rightarrow \infty} W\left(\beta_{i_{m}}, x_{0}, k_{n}\right)=\alpha=W\left(\beta, x_{0}, k_{n}\right) \in T_{n} x .
$$

Step 2. To prove that for all $x, y \in X$ and for all $n \in \mathbb{N}$ the following inequality is true,

$$
\int_{0}^{\delta\left(T_{n} x, T_{n} y\right)} \varphi(t) d t \leq k_{n} \int_{0}^{d(x, y)} \varphi(t) d t
$$

let $u \in T_{n} x=W\left(T x, x_{0}, k_{n}\right)$ and $v \in T_{n} y=W\left(T y, x_{0}, k_{n}\right)$. Then there exist $p \in T x$ and $q \in T y$ such that $u=W\left(p, x_{0}, k_{n}\right)$ and $v=W\left(q, x_{0}, k_{n}\right)$. Now, using (15) and (16) we obtain

$$
\begin{aligned}
\int_{0}^{d(u, v)} \varphi(t) d t & =\int_{0}^{d\left(W\left(p, x_{0}, k_{n}\right), W\left(q, x_{0}, k_{n}\right)\right)} \varphi(t) d t \leq k_{n} \int_{0}^{d(p, q)} \varphi(t) d t \\
& \leq k_{n} \int_{0}^{\delta(T x, T y)} \varphi(t) d t \leq k_{n} \int_{0}^{d(x, y)} \varphi(t) d t .
\end{aligned}
$$

As (18) is satisfied for every $u \in T_{n} x$ and $v \in T_{n} y$, inequality (17) is satisfied too.

Step 3 . In order to prove that the mapping $T_{n}$ has a unique fixed point $x_{n}$ such that $\left\{x_{n}\right\}=$ $T_{n} x_{n}$, we form an iterative sequence $\left\{y_{i}\right\}_{i \in \mathbb{N}}$ by choosing any $y_{0} \in X, y_{1} \in T_{n} y_{0}$ and $y_{2} \in$ $T_{n} y_{1}$. Obviously, $d\left(y_{1}, y_{2}\right) \leq \delta\left(T_{n} y_{0}, T_{n} y_{1}\right)$. Continuing that process, we get the sequence $\left\{y_{i}\right\}_{i \in \mathbb{N}}$ with the property that for every $i \in \mathbb{N}, y_{i} \in T_{n} y_{i-1}$ and $d\left(y_{i}, y_{i+1}\right) \leq \delta\left(T_{n} y_{i-1}, T_{n} y_{i}\right)$. Using the last inequality and (17), we get

$$
\begin{aligned}
\int_{0}^{d\left(y_{i}, y_{i+1}\right)} \varphi(t) d t & \leq \int_{0}^{\delta\left(T_{n} y_{i-1}, T_{n} y_{i}\right)} \varphi(t) d t \\
& \leq k_{n} \int_{0}^{d\left(y_{i-1}, y_{i}\right)} \varphi(t) d t \leq \cdots \leq k_{n}^{i} \int_{0}^{d\left(y_{0}, y_{1}\right)} \varphi(t) d t .
\end{aligned}
$$


If $i \rightarrow \infty$, by Lemma 2.7, we see that $\lim _{i \rightarrow \infty} d\left(y_{i}, y_{i+1}\right)=0$ and $\lim _{i \rightarrow \infty} \delta\left(T_{n} y_{i-1}, T_{n} y_{i}\right)=0$.

We claim that $\left\{y_{i}\right\}_{i \in \mathbb{N}}$ is a Cauchy sequence. Assumption that $\left\{y_{i}\right\}_{i \in \mathbb{N}}$ is not a Cauchy sequence implies that we can form a subsequence of pairs $\left\{\left(y_{i_{m}}, y_{j_{m}}\right)\right\}_{m \in \mathbb{N}}$ using the same procedure as in the proof of Theorem 4.1 and with same properties formulated in (10). Repeating the arguments from (11), we get

$$
\begin{aligned}
& \varepsilon \leq \lim _{m \rightarrow \infty} d\left(y_{i_{m}}, y_{j_{m}}\right) \leq \lim _{m \rightarrow \infty}\left(d\left(y_{i_{m}}, y_{j_{m}-1}\right)+d\left(y_{j_{m}-1}, y_{j_{m}}\right)\right) \leq \varepsilon \Rightarrow \\
& \lim _{m \rightarrow \infty} d\left(y_{i_{m}}, y_{j_{m}}\right)=\varepsilon,
\end{aligned}
$$

and by (17) we deduce that $\lim _{m \rightarrow \infty} \delta\left(T_{n} y_{i_{m}}, T_{n} y_{j_{m}}\right)<\varepsilon$. Finally, the following relation

$$
\begin{aligned}
\varepsilon & =\lim _{m \rightarrow \infty} d\left(y_{i_{m}}, y_{j_{m}}\right) \\
& \leq \lim _{m \rightarrow \infty}\left(\delta\left(y_{i_{m}}, T_{n} y_{i_{m}}\right)+\delta\left(T_{n} y_{i_{m}}, T_{n} y_{j_{m}}\right)+\delta\left(T_{n} y_{j_{m}}, y_{j_{m}}\right)\right)<0+\varepsilon+0=\varepsilon
\end{aligned}
$$

contradicts the assumption that $\left\{y_{i}\right\}_{i \in \mathbb{N}}$ is not a Cauchy sequence. Therefore, $\lim _{i \rightarrow \infty} y_{i}=$ $x_{n} \in T_{n} x$.

Next, we show that $x_{n}$ is a fixed point of $T_{n}$. Since

$$
\begin{aligned}
\delta\left(x_{n}, T_{n} x_{n}\right) & \leq d\left(x_{n}, y_{i+1}\right)+\delta\left(y_{i+1}, T_{n} x_{n}\right) \\
& \leq d\left(x_{n}, y_{i+1}\right)+\delta\left(T_{n} y_{i}, T_{n} x_{n}\right)
\end{aligned}
$$

and

$$
\int_{0}^{\delta\left(T_{n} y_{i}, T_{n} x_{n}\right)} \varphi(t) d t \leq k_{n} \int_{0}^{d\left(y_{i}, x_{n}\right)} \varphi(t) d t \stackrel{i \rightarrow \infty}{\longrightarrow} 0 \quad \Longrightarrow \quad \delta\left(T_{n} y_{i}, T_{n} x_{n}\right) \stackrel{i \rightarrow \infty}{\longrightarrow} 0,
$$

letting $i \rightarrow \infty$ in (19) and using the conclusion from (20), we get $\delta\left(x_{n}, T_{n} x_{n}\right)=0$, i.e., $\left\{x_{n}\right\}=$ $T_{n} x_{n}$. Observe that, according to (17), $x_{n}$ is a unique fixed point of $T_{n}$.

Step 4 . To finish the proof, it remains to establish the existence of a fixed point of the mapping $T$. The fact (from the last step) that $\left\{x_{n}\right\}=T_{n} x_{n}=W\left(T x_{n}, x_{0}, k_{n}\right), n \in \mathbb{N}$, yields the existence of $z_{n} \in T x_{n}$ such that $x_{n}=W\left(z_{n}, x_{0}, k_{n}\right), n \in \mathbb{N}$. By the compactness of the set $\overline{\bigcup_{n \in \mathbb{N}} T x_{n}} \subseteq \overline{T(X)}$, there exists a convergent subsequence $\left\{z_{n_{p}}\right\}_{p \in \mathbb{N}} \subset\left\{z_{n}\right\}_{n \in \mathbb{N}}, \lim _{p \rightarrow \infty} z_{n_{p}}=$ $z^{*} \in X$. The following relation

$$
\begin{aligned}
d\left(x_{n_{p}}, z^{*}\right) & \leq d\left(x_{n_{p}}, z_{n_{p}}\right)+d\left(z_{n_{p}}, z^{*}\right) \\
& =d\left(z_{n_{p}}, W\left(z_{n_{p}}, x_{0}, k_{n_{p}}\right)\right)+d\left(z_{n_{p}}, z^{*}\right) \\
& \leq k_{n_{p}} d\left(z_{n_{p}}, z_{n_{p}}\right)+\left(1-k_{n_{p}}\right) d\left(z_{n_{p}}, x_{0}\right)+d\left(z_{n_{p}}, z^{*}\right), \quad p \in \mathbb{N},
\end{aligned}
$$

when $p \rightarrow \infty$ (recall that $\left.\lim _{n \rightarrow \infty} k_{n}=1\right)$, leads to

$$
\lim _{p \rightarrow \infty} d\left(x_{n_{p}}, z^{*}\right)=0, \text { i.e., } \lim _{p \rightarrow \infty} x_{n_{p}}=z^{*} .
$$

Our assertion is that $\left\{z^{*}\right\}=T z^{*}$. To confirm that, we consider the following inequality:

$$
\delta\left(z^{*}, T z^{*}\right) \leq d\left(z^{*}, z_{n_{p}}\right)+\delta\left(z_{n_{p}}, T z^{*}\right) .
$$


From $z_{n_{p}} \in T x_{n_{p}}$, we have $\delta\left(z_{n_{p}}, T z^{*}\right) \leq \delta\left(T x_{n_{p}}, T z^{*}\right)$ and therefore

$$
\int_{0}^{\delta\left(z_{n_{p}}, T z^{*}\right)} \varphi(t) d t \leq \int_{0}^{\delta\left(T x_{n_{p}}, T z^{*}\right)} \varphi(t) d t \leq \int_{0}^{d\left(x_{n_{p}}, z^{*}\right)} \varphi(t) d t \stackrel{p \rightarrow \infty}{\longrightarrow} 0
$$

By Lemma 2.7 we obtain $\delta\left(z^{*}, T z^{*}\right)=0$, that is, $\left\{z^{*}\right\}=T z^{*}$.

\section{Competing interests}

We confirm that none of the authors have any competing interests in the manuscript.

\section{Authors' contributions}

All authors jointly worked on the results, and they read and approved the final manuscript.

\section{Author details}

${ }^{1}$ Faculty of Technical Science, University of Novi Sad, Novi Sad, Serbia. ${ }^{2}$ Faculty of Science, University of Novi Sad, Novi Sad, Serbia. ${ }^{3}$ Faculty of Technology, University of Novi Sad, Novi Sad, Serbia.

\section{Acknowledgements}

The authors are very grateful to the anonymous referees for their careful reading of the paper and suggestions which have contributed to the improvement of the paper. The authors are partially supported by Ministarstvo prosvete i nauke Republike Srbije (Grants No.: 174019, 174024, 174025, 174009).

Received: 22 May 2015 Accepted: 4 August 2015 Published online: 19 August 2015

\section{References}

1. Banach, S: Sur les opérations dans les ensembles abstraits et leur application aux équations intégrales. Fundam. Math. 3, 133-181 (1922)

2. Nadler, SB: Multivalued contraction mappings. Pac. J. Math. 30, 475-478 (1969)

3. Branciari, A: A fixed point theorem for mappings satisfying a general contractive condition of integral type. Int. J. Math. Math. Sci. 29(9), 531-536 (2002)

4. Ali, MA, Kamram, T, Karapinar, E: An approach to existence of fixed points of generalized contractive multivalued mappings of integral type via admissible mapping. Abstr. Appl. Anal. 2014, Article ID 141489 (2014)

5. Ali, MU, Kamran, T: On $\left(\alpha^{*}, \psi\right)$-contractive multi-valued mappings. Fixed Point Theory Appl. 2013, 137 (2013)

6. Alsulami, HH, Karapinar, E, O'Regan, D, Shahi, P: Fixed points of generalized contractive mappings of integral type. Fixed Point Theory Appl. 2014, 213 (2014)

7. Altun, I, Turkoglu, D: Some fixed point theorems for mappings satisfying contractive condition of integral type on d-complete topological spaces. Fasc. Math. 42, 5-15 (2009)

8. Chauhan, S, Karapinar, E: Some integral type common fixed point theorems satisfying $\Psi$-contractive conditions. Bull. Belg. Math. Soc. Simon Stevin 21(4), 593-612 (2014)

9. Karapinar, E, Shahi, P, Tas, K: Generalized $\alpha$ - $\psi$-contractive type mappings of integral type and related fixed point theorems. J. Inequal. Appl. 2014, 160 (2014)

10. Rhoades, BE: Two fixed-point theorems for mappings satisfying a general contractive condition of integral type. Int. J. Math. Math. Sci. 63, 4007-4013 (2003)

11. Turkoglu, D, Altun, l: A fixed point theorem for multi-valued mappings and its applications to integral inclusions. Appl. Math. Lett. 20, 563-570 (2007)

12. Vijayaraju, P, Rhoades, BE, Mohanraj, R: A fixed point theorem for a pair of maps satisfying a general contractive condition of integral type. Int. J. Math. Math. Sci. 2005(15), 2359-2364 (2005)

13. Khan, MS, Swaleh, M, Sessa, S: Fixed point theorems by altering distances between the points. Bull. Aust. Math. Soc. 30, 1-9 (1984)

14. Takahashi, W: A convexity in metric space and nonexpansive mappings. Kodai Math. Semin. Rep. 22(2), 142-149 (1970)

15. Liu, Z, Li, J, Kang, SM: Fixed point theorems of contractive mappings of integral type. Fixed Point Theory Appl. 2013, 300 (2013) 